\title{
Human Mars Landing Site and Impacts on Mars Surface Operations
}

\author{
Ben Bussey \\ NASA HQ - 7R76 \\ 300 E Street $S W$ \\ Washington DC 20546 \\ 202-358-0954 \\ david.b.bussey@nasa.gov
}

\author{
Stephen J. Hoffman \\ Science Applications International \\ Corp. \\ 2450 NASA Parkway \\ Houston, TX 77058 \\ 281-483-9264 \\ stephen.j.hoffman@nasa.gov
}

Abstract - This paper describes NASA's initial steps for identifying and evaluating candidate Exploration Zones (EZs) and Regions of Interests (ROIs) for the first human crews that will explore the surface of Mars. NASA's current effort to define the exploration of this planet by human crews, known as the Evolvable Mars Campaign (EMC), provides the context in which these EZs and ROIs are being considered. The EMC spans all aspects of a human Mars mission including launch from Earth, transit to and from Mars, and operations on the surface of Mars. An EZ is a collection of ROIs located within approximately 100 kilometers of a centralized landing site. ROIs are areas relevant for scientific investigation and/or development/maturation of capabilities and resources necessary for a sustainable human presence. The $\mathrm{EZ}$ also contains one or more landing sites and a habitation site that will be used by multiple human crews during missions to explore and utilize the ROIs within the EZ. With the EMC as a conceptual basis, the EZ model has been refined to a point where specific site selection criteria for scientific exploration and in situ resource utilization can be defined. In 2015 these criteria were distributed to the planetary sciences community and the in situ resource utilization and civil engineering communities as part of a call for EZ proposals. The resulting "First Landing Site/Exploration Zone Workshop for Human Missions to the Surface of Mars" was held in October 2015 during which 47 proposals for EZs and ROIs were presented and discussed. Proposed locations spanned all longitudes and all allowable latitudes (+/- 50 degrees). Proposed justification for selecting one of these EZs also spanned a significant portion of the scientific and resource criteria provided to the community. Several important findings resulted from this Workshop including: (a) a strong consensus that, at a scale of $100 \mathrm{~km}$ (radius), multiple places on Mars exist that have both sufficient scientific interest to sustain multiple crews of exploring astronauts, AND potential resource deposits for ISRU indicating the current $\mathrm{EZ}$ definition is viable and should be retained for now, (b) new data types (needed for more definitive analysis of EZs) argued strongly for a new orbiter mission, and possibly one or more surface missions, to obtain these data, (c) a general consensus that this Workshop was an excellent start to identifying a place where future human missions to Mars can productively explore this planet and learn to live and work there for the long term. Building on these findings, HEOMD and SMD are: (a) refining the EZ selection criteria and overall selection process to improve on lessons learned from the first EZ workshop, (b) using these proposed locations to develop "reference EZs" for assessment purposes (primarily engineering assessments), (c) gathering data and conducting analyses to better understanding the different potential sources for water, including the ease of extraction and purification, and (d) assessing trends in additional data that are needed to better characterize EZs proposed at the workshop and how these data needs impact the design and operation of future robotic Mars missions.

\section{Table of Contents}

1. INTRODUCTION ...............................................1

2. The Evolvable Mars Campaign .................2

3. CONCEPT OF OPERATIONS FOR HUMAN CREWS ON MARS .3

4. EXPLORATION ZONE REPRESENTATIVE

EXAMPLE. .5

5. Site SELECTION CRITERIA .................................6

6. THE FirST LANDING SITE/EXPLORATION ZONE WORKSHOP FOR HUMAN MISSIONS TO THE SURFACE OF MARS .

7. RESULTS AND FINDINGS FROM THE FIRST

LANDING SITE/EXPLORATION ZONE

WORKSHOP FOR HUMAN MISSIONS TO THE

SURFACE OF MARS 8

8. CONCLUSION...................................................10

APPENDICES.................................................12

A. SCIENCE CRITERIA FOR EZ Selection........12

B. ICE CRITERIA FOR EZ SELECTION ...............15

C. Steering CommitTeE Membership for THE FIRST LANDING SITE/EXPLORATION ZONE WORKSHOP FOR HUMAN MISSIONS TO

THE SURFACE OF MARS...............................18

D. Summary of Proposed EZ AND ROI

LOCATIONS AND KEY CHARACTERISTICS...19

REFERENCES...................................................21

BIOGRAPHY ..................................................21

\section{INTRODUCTION}

NASA has begun a process to identify and discuss candidate locations where humans could land, live and work on the martian surface. This process is being carried out as a cooperative effort by NASA's Human Exploration and Operations Mission Directorate (HEOMD), responsible for future human mission preparations, and the Science Mission 
Directorate (SMD), responsible for the on-going Mars Exploration Program of robotic vehicles in orbit and on the surface of Mars. Both of these Directorates have a significant interest in this process as these candidate locations will be used by NASA as part of a multi-year effort to determine where and how humans could explore Mars. In the near term this process includes: (a) identifying locations that would maximize the potential science return from future human exploration missions, (b) identifying locations with the potential for resources required to support humans, (c) developing concepts and engineering systems needed by future human crews to conduct operations within a candidate location, and (d) identifying key characteristics of the with utilization of in situ resources to make the entire exploration process more sustainable. Using EMC study results, such as these concept of operation assessments, in conjunction with science objectives for Mars exploration that are maintained by the Mars Exploration Program Analysis Group (MEPAG), led to a set of site selection criteria which are described in the next section. These criteria were circulated among the science and resource utilization communities as part of a call for proposed EZs and ROIs. A summary of the resulting proposals, presented at the first of several workshops on this topic, is presented next. This paper concludes with a discussion of the findings from this first workshop and plans for use of the findings along with

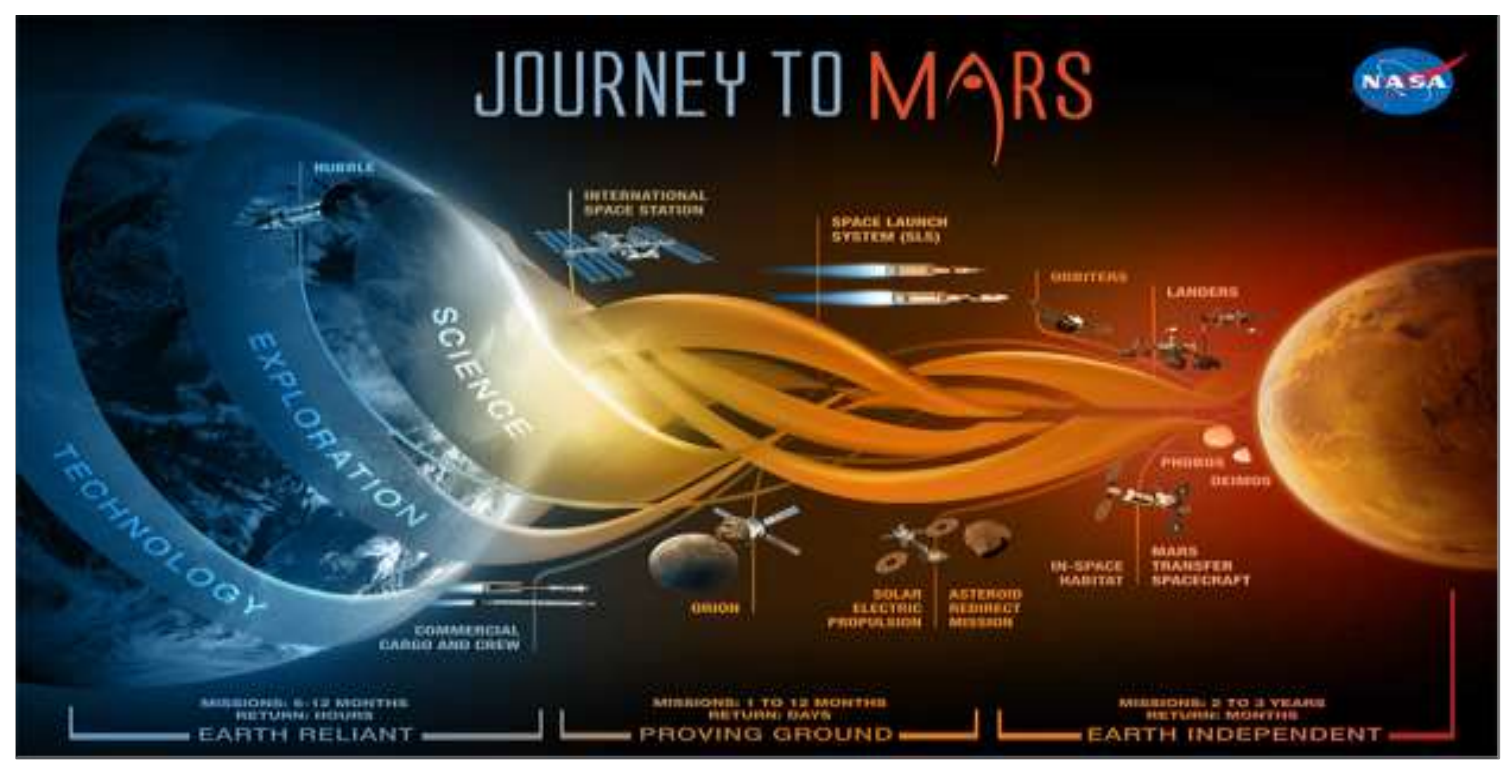

Figure 1 The multiple phases and evolutionary streams in NASA's Evolvable Mars Campaign.

proposed candidate locations that cannot be evaluated using existing data sets, thus helping to define precursor measurements needed in advance of human missions.

This paper summarizes the current state of NASA's effort to identify viable locations for future human missions to Mars and the activities that contributed to this current state. At present NASA is assessing different options for conducting these future human missions to Mars by means of coordinated studies, the results of which are assembled into an end-to-end description collectively known as the Evolvable Mars Campaign (EMC). The next section contains a brief description of the EMC. The concepts of an Exploration Zone (EZ) and a Region of Interest (ROI) are introduced in this section as a mechanism to help organize the key criteria used to identify candidate sites on Mars. This is followed by a more detailed description of the concept of operations for human crews on the surface of Mars. One hypothetical EZ, an area centered on Jezero Crater (drawn from a previous study by the Human Exploration of Mars - Scientific Analysis Group, or HEM-SAG), is used to illustrate how this concept of operations will be implemented - from initial selection of the EZ site to emplacement of required surface infrastructure to ROI exploration by robots and humans along preparations for subsequent workshops.

\section{The Evolvable Mars Campaign}

Over the past several years, NASA has been implementing the NASA Authorization Act of 2010 [1]. The Act calls on NASA to (1) develop and evolve the Space Launch System (SLS) rocket and Orion crew vehicle and (2) to expand human exploration beyond low Earth orbit to cis-lunar space destinations, leading eventually to the international exploration of Mars. To satisfy the second of these actions NASA is defining a long-term, flexible and sustainable deep space exploration architecture termed the "Evolvable Mars Campaign" (EMC). (See Figure 1 and reference [2]) In short, the EMC provides a basis for (1) architecture development, and (2) identification and analysis of trade studies with NASA's partners and stakeholders. NASA is structuring the EMC such that it can reasonably adjust to changing priorities across the decades. From this work will emerge the roadmap NASA will follow through cis-lunar space to pioneer Mars. [3]

To guide studies associated with the EMC over the past several years, a set of ground-rules and assumptions were 
established to examine one particular approach to the human exploration of Mars that would satisfy objectives set out in guiding documents such as the National Space Policy of 2010 [4] and the NASA Authorization Act of 2010. Principle among these ground-rules and assumptions that are relevant to activities and results described in this paper was a choice to concentrate all of the surface assets needed to support human exploration at a single location and then send future crews to this site for subsequent missions in the EMC. This contrasts with the scenario considered in Design Reference Architecture 5.0 (DRA 5.0) [5] in which a campaign of three missions sends crews to different locations on Mars. spacecraft will be tasked to gather data from specific Mars surface sites within the candidate EZs to support further EMC studies and to assist in the process of selecting a final EZ.

\section{CONCEPT OF OPERATIONS FOR HUMAN CREWS ON MARS}

In the previous section the EMC was noted to differ in one significant respect from DRA 5.0 - with the EMC, a single surface site would be chosen for exploration by all crews sent to Mars. However, the approach used by these crews to explore what we now called ROIs would be comparable to the "Commuter" approach adopted in DRA 5.0 [5, Section

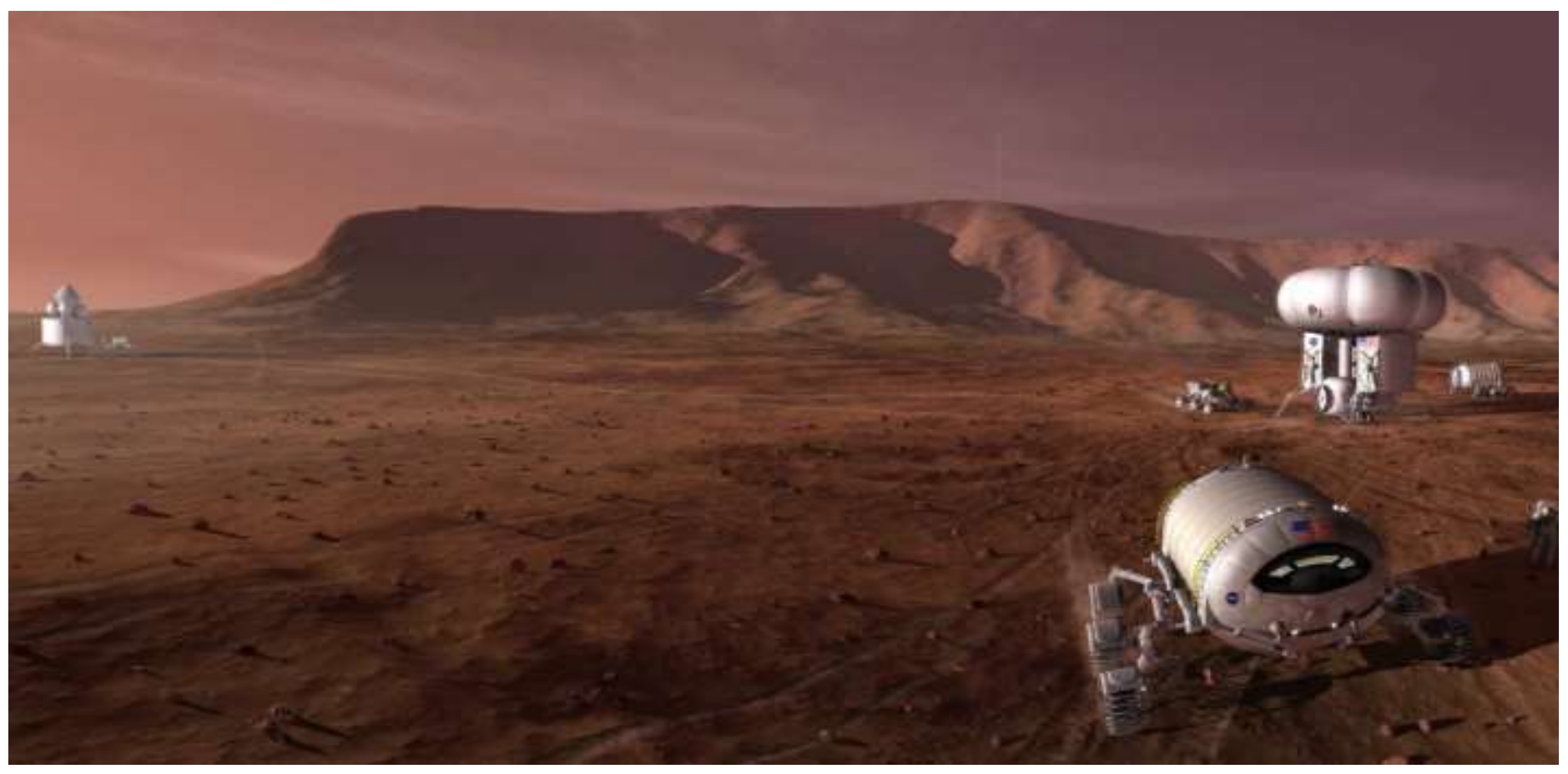

Figure 2 A Mars surface mission will require multiple elements, including large landers, ascent vehicles, and rovers, to complete all objectives.

One facet of these EMC studies is an effort to better understand details of the operations that will be carried out by human crews on Mars and the systems and infrastructure needed to support these operations. The next section will discuss these surface operations in more detail, but one outcome of the choice to concentrate all surface assets at a single location is the concept of an Exploration Zone (EZ) that describes the features of a surface location where the activities of the human crews will take place. An EZ is a collection of Regions of Interest (ROIs) that are located within approximately 100 kilometers of a centralized landing site. ROIs are areas that are relevant for scientific investigation and/or development/maturation of capabilities and resources necessary for a sustainable human presence. The EZ also contains multiple landing sites as well as a habitation area that will be used by multiple human crews during missions to explore and utilize the ROIs within the EZ. As NASA identifies candidate locations that exhibit the potential to be viable EZs, existing and future robotic
2.1]. DRA 5.0 describes the "Commuter" approach as follows:

The nominal surface mission scenario adopted for DRA 5.0 is the so-called "Commuter" reference architecture, which would have a centrally located, monolithic habitat, two small pressurized rovers, and two unpressurized rovers (roughly equivalent to the lunar rover vehicle (LRV) that was used in the Apollo missions to the Moon). This combination of habitation and surface mobility capability would allow the mission assets to land in relatively flat and safe locations, yet provides the exploration range that would be necessary to reach nearby regions of greater geologic diversity. Power for these systems would be supplied by a nuclear power plant that was previously deployed with the DAV [descent-ascent vehicle, referred to now in the EMC as the Mars Ascent Vehicle or MAV] and used to make a portion of the ascent propellant. Traverses would be a significant feature of the exploration 


\section{Emplacement}

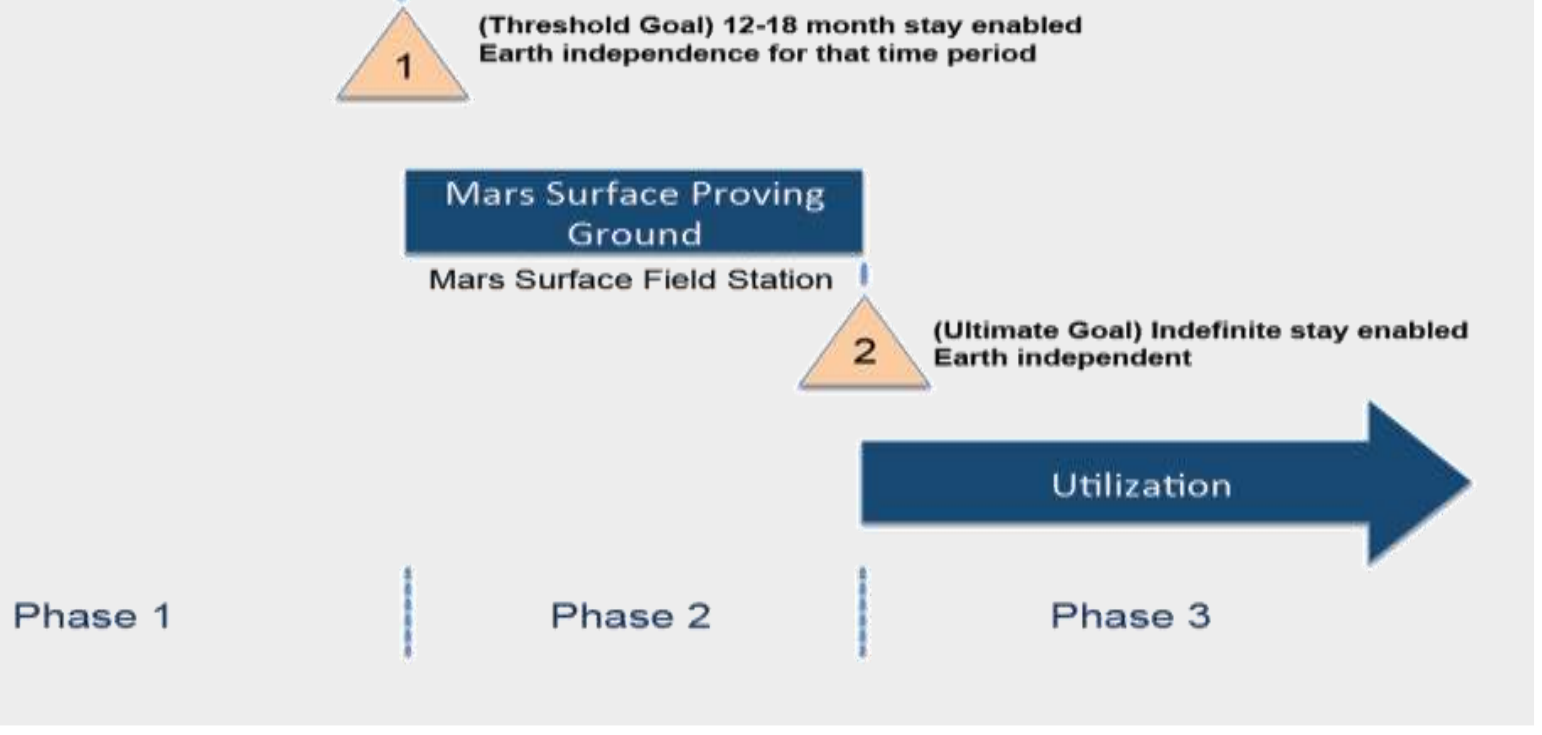

Figure 3 A three-phased approach to the evolution of a Mars Surface Field Station is envisioned.

strategy that would be used in this scenario, but these traverses would be constrained by the capability of the small pressurized rover. In this scenario, these rovers have been assumed to have a modest capability, notionally a crew of two, at least 200 kilometers total distance before being re-supplied, and 1- to 2-week duration. Thus, on-board habitation capabilities would be minimal in these rovers. However, these rovers are assumed to be nimble enough to place the crew in close proximity to features of interest (i.e., close enough to view from inside the rover or within easy extravehicular activity (EVA) walking distance of the rover).

Figure 2 visually illustrates how these multiple surface elements would be located in what is now called the centralized landing area and habitation zone. To the left in this image is the DAV / MAV that is located a significant distance from the habitat, seen in the center right of the image. This separation distance is the result of a precaution taken to separate these landers so that debris lofted by the terminal descent rocket engines does not damage any previously landed system. The area occupied by both of these landers is also relatively flat and free of significant objects or terrain features that would pose a hazard to these large landers and the crews or cargo they carry. With the choice in the EMC for multiple crews to return to a single location, this places some additional considerations on selecting a site at which many of these large landers can be safely landed in relatively close proximity while also protecting the surface infrastructure from debris (Note: A technological capability called Autonomous Landing and Hazard Avoidance Technology -- ALHAT -- has been demonstrated in simulations on Earth. This capability will allow a lander to be landed within 100 meters of a designated location on Mars. This will allow multiple landers to be landed within relatively close proximity as illustrated here. Details can be found in DRA 5.0 [5] and other sources.)

Studies carried out as part of the EMC recognized that in addition to scientific questions there would be "known unknowns" associated with exploration of Mars that can only be addressed and understood by human crews living and working on Mars [6]. Several of the more significant "known unknowns" that will need to be addressed include the following:

- Human physiological reaction to the Mars environment (e.g., gravity, radiation, dust, etc.)

- Plant physiological reaction to the Mars environment (e.g., gravity, radiation, lighting, etc.)

- Sources and extraction/processing technology for water

- Martian civil engineering "best practices" (e.g., surface preparation/stabilization)

- Martian chemical engineering "best practices."

Addressing these questions could require a significant amount of time to understand; possibly spanning the mission of several crews. The EMC has recently adopted a threephased approach to establishing a single surface site that is capable of addressing these questions as well as equally important scientific questions [6]. Figure 3 illustrates these 
three phases in the development of this surface site. The "proving ground" phase of this evolution lends itself to a "field station" approach to the development of this central habitation zone / landing site portion of the EZ. In this context, a working definition of a "field station" is as follows [7]: one representative EZ. In this case, one of the sites considered in the MEPAG Human Exploration of Mars Science Analysis Group (HEM-SAG) report [8] - an area centered on Jezero Crater - is used.

Figure 4 is a figure from the HEM-SAG report showing what we are now calling a proposed EZ with a notional landing site

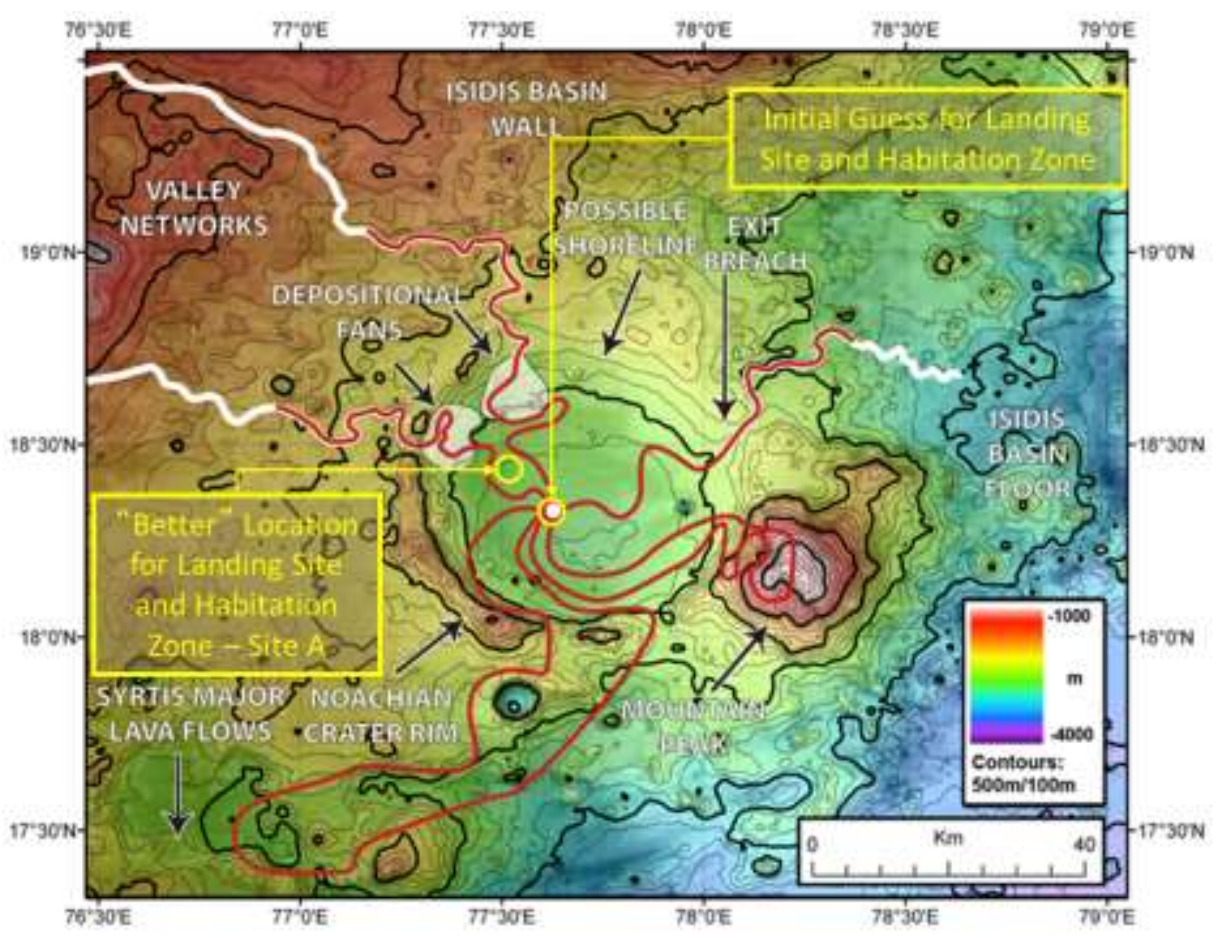

Figure 4 A representative site on Mars with a diverse set of exploration regions. This image is representative of a preliminary proposal that is interesting enough to warrant more detailed analysis.

Field stations create a bridge between natural environments and (Earth-based) research laboratories. Research laboratories offer considerable power to conduct analyses in a predictable environment and to infer cause and effect from manipulative experiments, but they may miss factors that turn out to be critical in a natural environment. Field studies can encompass the full range of relevant interactions and scales, but they are not as tightly controlled. By offering access to both laboratories and field environments, Field Stations combine the best of both worlds.

Identifying and selecting an EZ that possesses all of these landing site features while also exhibiting significant ROI diversity and scientific importance poses a substantial challenge in order for these multiple crews to carry out productive missions.

\section{EXPLORATION ZONE REPRESENTATIVE EXAMPLE}

To illustrate the type of steps that could be expected in assessing a proposed EZ for its applicability in this threephase strategy, this section briefly follows this process for located roughly in the center of the crater. Several traverses to investigate surface features (what we are now calling science ROIs) are shown. Investigations associated with these features cover a diverse range of scientific disciplines and results that can be traced to many of the scientific goals recommended by MEPAG for Mars exploration [9]. These investigations and traverses are sufficiently extensive to potentially require the efforts of several crews to complete in a thorough manner.

At this point, existing data sets would be examined in and around this hypothetical EZ to refine the potential scientific investigations at the initially identified ROIs and to search for additional relevant ROIs within the 100 kilometer radius allowed for within an EZ. In addition, ROIs with resource utilization potential would be identified and the viability of the proposed landing site and habitation zone would be assessed. Figure 5 identifies several additional, but notional, ROIs that lie within the 100 kilometer allowable range. Two notional resource ROIs are shown within the crater itself, both of which are reasonably close to the proposed landing site.

For this particular example, an examination of HiRISE imagery around the initially proposed landing site indicates 
that the area was likely unsuitable for repeated landings and use as a habitation zone. However, a suitable location was found in this imagery, resulting in a refined location for the landing site and habitation zone - this is noted as "Site A" in Figure 4 and depicted as a small inset in Figure 5. following section will discuss a more detailed set of site selection criteria that will all need to be taken into account as these proposed EZs are assessed. As these assessments proceed, it is likely that additional data will be required to verify the features or investigations initially proposed for the EZ. These additional data needs will become the source of

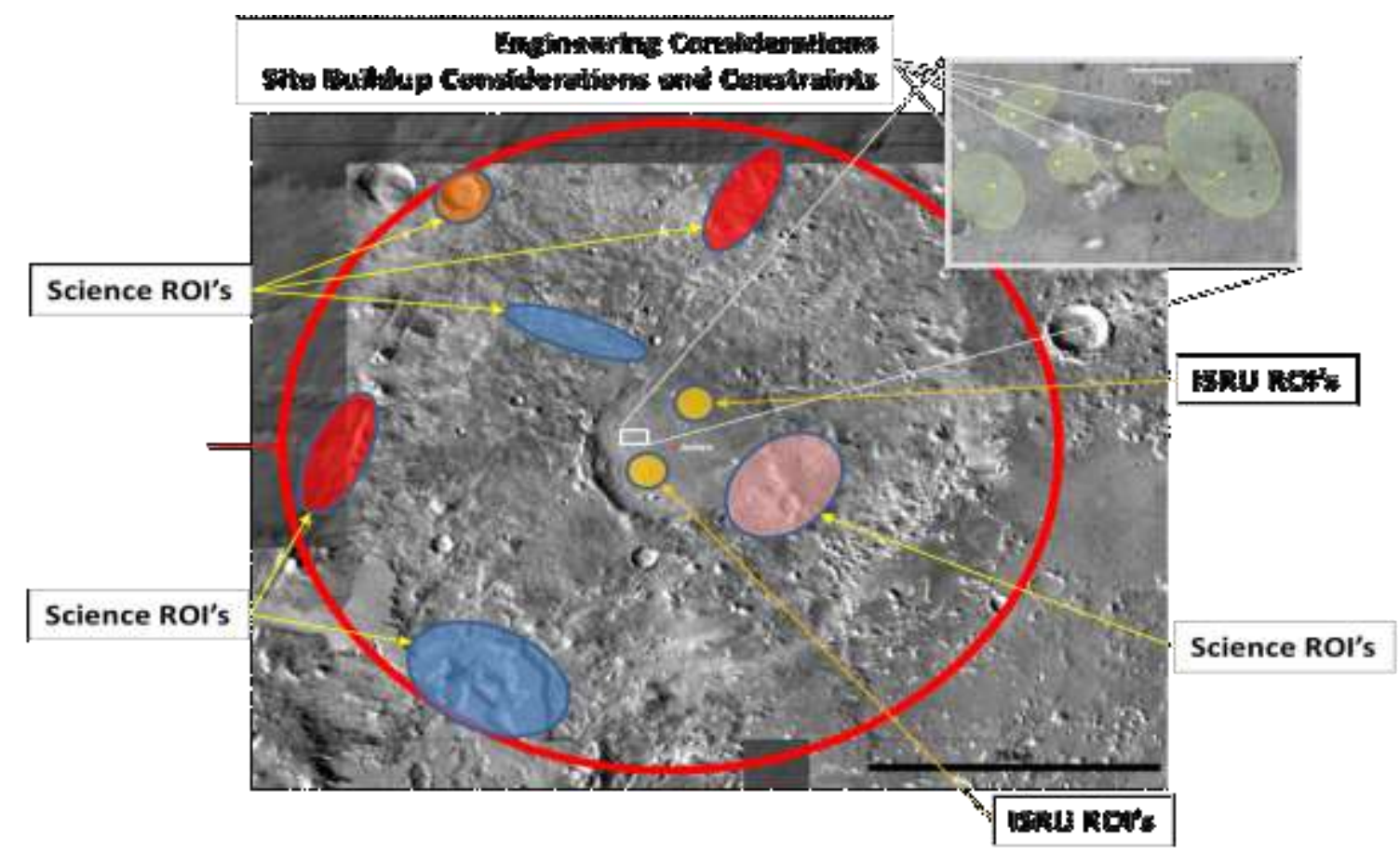

Figure 5 The same representative site as shown in Figure 4 noting the limits of the "Exploration Zone" and location of both the "habitation zone" and "regions of interest."

The small inset in Figure 5 is shown in larger scale in Figure 6 and illustrates the considerations taken into account when assessing the landing site and habitation zone. The low hills (rising roughly 40-50 meters above the surrounding terrain) in the center of Site A would make a suitable feature for terrain-relative navigation likely to be used by the landing system for final approach and terminal descent. The area indicated as the "primary lander zone" would be used by MAV vehicles and has space for at least two active MAVs to be located in this area without risk of lander-created debris damage discussed previously (the blue circle is an indication of the potential range of this flying debris). The areas indicated as "secondary landing zones" would be used by cargo-only landers and would be situated closer to the proposed habitation zone, which for this example was chosen to be near the low hills at the center of Site A. A relatively flat area located among the low hills was identified that would make a suitable location for the fission power plant that will supply power for the entire landing site and habitation zone: it is located roughly equidistant from the habitation zone and primary lander zone and the low hills surrounding it provide a natural form of radiation protection.

This example illustrates a simplified version of a few of the assessments likely to be required for each proposed EZ. The tasking requests for existing assets at Mars or will provide input for the definition of future Mars missions and associated instruments.

\section{Site Selection Criteria}

During 2015 the EZ model was refined to a point where specific site selection criteria for scientific exploration and in situ resource utilization could be defined. For criteria related to scientific interests, MEPAG chartered the Scientific Objectives for the Human Exploration of Mars - Science Analysis Group (HSO-SAG) to develop criteria for ROIs that address scientific objectives at Mars and are consistent with the previously described concept of operations for human missions. A separate group - the ISRU and Civil Engineering Working Group (ICE-WG) - was created to prepare a similar set of criteria for resource and civil engineering related ROIs. These criteria were circulated to the planetary sciences community and the in situ resource utilization and civil engineering community as part of a call for EZ proposals. These criteria can be found in Appendices A and B. 


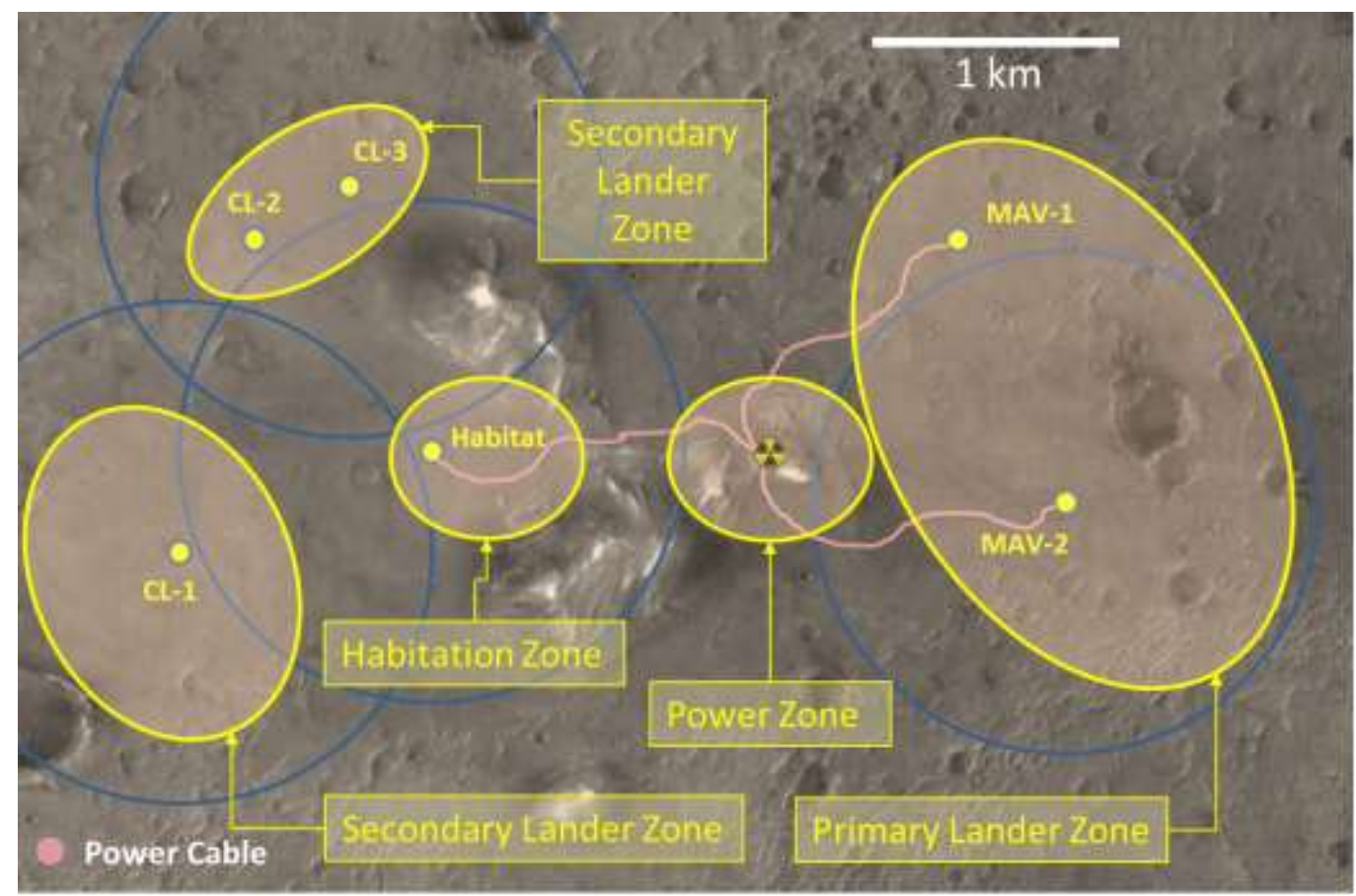

Figure 6 A more detailed image of specialized zones that will be defined within "habitation zones" as these areas are identified.

\section{THE FIRST LANDING SITE/EXPLORATION ZONE WORKSHOP FOR HUMAN MISSIONS TO THE SURFACE OF MARS}

The "First Landing Site/Exploration Zone Workshop for Human Missions to the Surface of Mars," at which proposals for EZs and ROIs were presented and discussed, was held on 27-30 October 2015. A Steering Committee with representation from both the Human Exploration and Operations Mission Directorate (representing the human spaceflight and exploration perspective) and the Science Mission Directorate (representing the robotic spaceflight and scientific investigation perspective) was assembled to make preparations for this Workshop. The members of this Steering Committee are listed in Appendix C. The announced purpose of this workshop was to identify and discuss candidate locations where humans could land, live, and work on the martian surface. The announcement for this workshop provided the following information to those who may have been interested in proposing EZs or ROIs:

- $\quad$ Each EZ will have a collection of diverse ROIs that are all within $\sim 100$ kilometers of a single plausible landing site and accessible via traversable routes from that landing site. (There are two main types of ROI: science ROIs and resource ROIs. Specific criteria for science and resource ROIs was summarized in Section 5. An ROI can be of any size and can meet one or multiple criteria.)

- Multiple crews will visit the same EZ, gradually expanding the amount and depth of exploration of that region. A science ROI might therefore be visited multiple times, if required, and resource ROI(s) should be of a scale that offers the potential to provide usable commodities for multiple crews.

- The viability of an identified "plausible" landing site and traverse routes will be assessed separately by engineering teams familiar with the systems being considered for these human missions. However, we do ask that you identify a plausible Mars landing site that has these characteristics: (a) located between $+/-50$ degrees latitude, (b) less than +2 kilometers altitude (Mars Orbiter Laser Altimeter (MOLA) reference), (c) an area of approximately 25 square kilometers within which the terrain is generally level (slopes less than $\sim 10$ degrees) and significantly devoid of landing hazards (e.g., large and/or closely concentrated craters, mountainous terrain, broken/jumbled/chaotic terrain, extensive dune fields, etc.), and (d) does not contain thick deposits of fine-grained dust (e.g., extremely low thermal inertia and high albedo).

- $\quad$ These candidate EZs will be used by HEOMD and SMD as part of the multi-year process of determining where and how we would like to explore Mars with humans. In the near term this process includes: (a) identifying locations that would maximize the potential science return from future human exploration missions, (b) identifying locations with the potential for resources required to support humans, (c) developing concepts and engineering systems needed by future human crews to conduct operations within an EZ, and (d) identifying key 


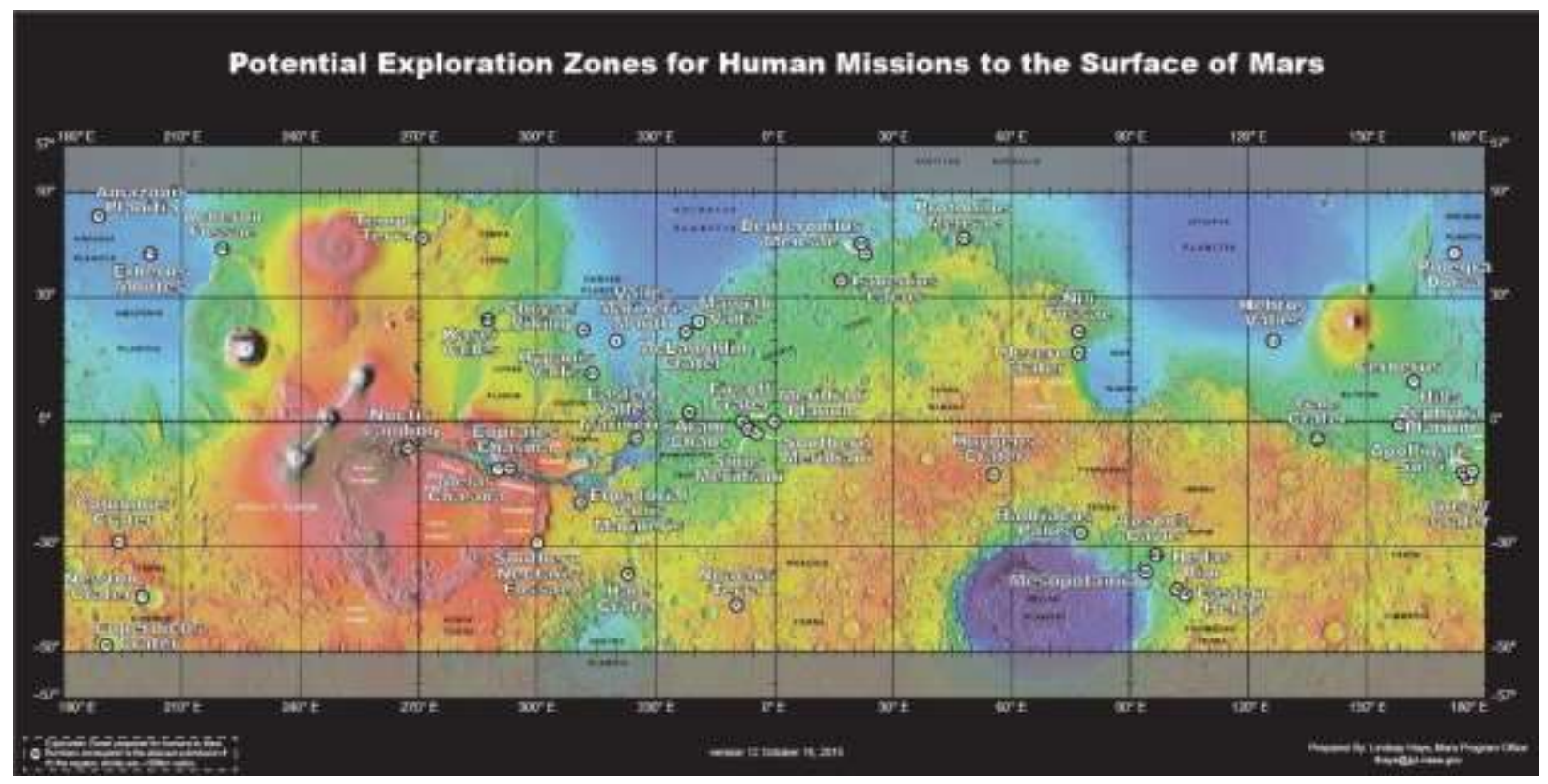

Figure 7 Exploration Zones as proposed for the First Landing Site/Exploration Zone Workshop.

characteristics of the proposed candidate EZs that cannot be evaluated using existing data sets, thus helping to define precursor measurements needed in advance of human missions. Existing and future robotic spacecraft will be tasked to gather data from specific Mars surface sites within the representative EZs to support these HEOMD and SMD activities.

- An optimal submission would be an EZ that contains several science ROIs (of different types) as well as at least one potential resource ROI. However, all smallerscale submissions (e.g. an EZ with just science ROIs) will be considered.

- For this first workshop, we are not expecting EZ submissions to have all of these ROIs. But we are looking for EZs that have as many of these ROIs as possible. We are also very interested in other types of ROIs. Since the human base will be a permanent base, diversity of science objectives is critical.

In response to this call for proposals, $47 \mathrm{EZs}$ were accepted for presentation from among all of the submissions received. A map of the submitted EZs is shown in Figure 7, and these presentations are summarized in Appendix D of this paper.

\section{RESULTS AND FINDINGS FROM THE FIRST LANDING SITE/EXPLORATION ZONE WORKSHOP FOR HUMAN MISSIONS TO THE SURFACE OF MARS}

Approximately 175 people - including scientists, engineers, technologists, industry representatives and the press attended the Workshop in person. An additional approximately 280 people from around the world watched the Workshop via a UStream connection.

Presentations for 44 of the 45 accepted abstracts were made during the Workshop. Copies of these presentations can be found at: http://www.nasa.gov/feature/mars-human-landingsite-workshop-presentations. The location of these EZs spanned most of the range of latitude, longitude, and elevation allowed in the call for proposals, as can be seen in Figure 7. A more detailed version of the map can be found at: http://www.nasa.gov/sites/default/files/atoms/files/explorati on-zone-map-v10.pdf. Figure 8 shows a different view of the distribution of these sites across the allowed range of elevation and latitude, using a graphical format.

A diverse range of exploration objectives (scientific and resources) were described in these abstracts and associated presentations, all of which are posted at the previously mentioned location. Each presentation included a section describing the current best estimate of additional data needed for these assessments. The participants were invited to answer several questions and submit additional comments regarding this Workshop via email for a period of several weeks. The comment period closed in mid-December 2015 and the comments received are still being reviewed and discussed by the Workshop Steering Committee. However, a preliminary review of participant responses indicates the following:

- More than half of the presentations were considered by the attendees to have made a strong case for the merits of sending multiple crews to the EZ; only about one-sixth of the presentations were considered to have presented insufficient data to make an assessment. 
- Slightly more than one third of the EZs presented should reconsider their requested highest priority data - most often by requesting data from a different instrument, but potentially also selecting a different ROI to target. acknowledged a need to better understand the kinds of raw materials, and properties of those materials, that are sought after by the ISRU community. Similarly, the ISRU community acknowledged a need to better understand the kinds of raw materials found on Mars and their distribution
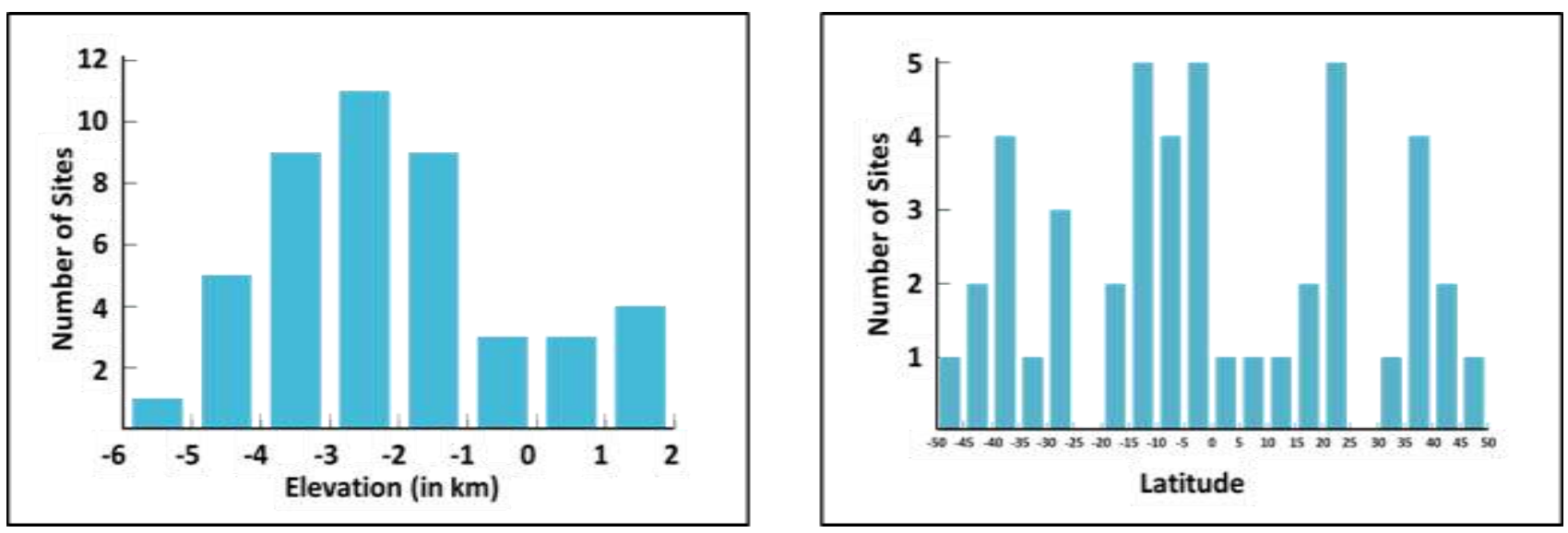

Figure 8 Distribution of the proposed Exploration Zones by elevation and by latitude.

On the final day of the Workshop time was set aside for the organizers and participants to discuss impressions based on the previous days of presentations with a focus on how to build on the process started at this Workshop. A summary of other important comments from this discussion include the following:

The viability/value of the EZ concept in describing and assessing human exploration on Mars.

There was strong consensus that at a scale of $100 \mathrm{~km}$ (radius), multiple places on Mars exist that have both sufficient scientific interest to sustain multiple crews of exploring astronauts, AND potential resource deposits for In-Situ Resource Utilization (ISRU). At this point in the process of identifying the preferred EZ there is no rationale to change this dimension (e.g. to $150 \mathrm{~km}$ radius). The concept of recurring visits to the same site (as opposed to landing in multiple different places) was a Workshop assumption that was not discussed.

Very few sites were proposed poleward of 45 degrees, even though by the guidelines set for this Workshop, sites up to 50 degrees both north and south were allowed. However, a number of important candidate sites were proposed in the latitude range $40-45 \mathrm{~N}$ and $40-45 \mathrm{~S}$ (see Figure 7). Within these belts, ice is going to be the most continuous, and the overburden that needs to be removed will be thinnest.

Data and Data Analysis.

There was general agreement that the addition of accessible resources to traditional scientific objectives as criteria for a desirable Exploration Zone expanded the need for new data types and new data analyses. Those participants who count themselves among the traditional science community across the surface (and subsurface).

Both communities acknowledged that there is a substantial, but not complete, overlap between the data sets needed by each community among the data currently being gathered as part of scientific investigations at Mars. In some cases additional data of the type that can currently be acquired is needed for EZs proposed in areas that have not been studied in detail. In other cases additional data of the type that can currently be acquired is needed at higher resolution (e.g., imagery). In a substantial number of cases new data is needed that has never been gathered before (e.g., radar at shallow depths) and require new instruments in orbiting spacecraft or may require data acquired from the surface or subsurface. There was agreement that these new data types argued strongly for a new orbiter mission, and possibly one or more surface missions, to obtain these data. The need for surface missions(s) targeted for candidate EZs (and possibly for specific ROIs with the EZs) was particularly apparent for resources-related questions associated with determining the quantity of the target feedstock (e.g., what is the vertical distribution of the feedstock of those materials for which only surface data are available) and the quality of the feedstock (i.e., verifying, or refining, estimate based on remote sensing data).

One key result of the workshop was the agreement that we need to better understand the relative merits of the multitude different sources for water. Water sources discussed, include

1. Buried ice deposits

2. Hydrated minerals (several types including poly hydrated sulfates) 


\section{Hydrated dune fields}

\section{Recurring Slope Lineae (RSLs)}

Future work needs to consider the relative ease and efficiency of extracting clean water from these sources. Factors include the mass, power and complexity of the systems needed to excavate, process and purify the water.

Presenters generally acknowledged that additional analyses of existing data, plus new data when it is available, will be required to improve their assessment of features within their proposed EZs relative to the criteria distributed with the call for proposals. Each of the presentations included a section describing the current best estimate of additional data needed for these assessments.

\section{The Next Workshop(s).}

Dialog between science and ISRU/Civil Engineering (CE) communities was generally acknowledged as one of the major benefits of this Workshop. Finding means to continue and expand this cross-communities dialog was also encouraged but there were many different approaches suggested for accomplishing this. Additional workshops, perhaps focused on different aspects of selecting an EZ, is one approach that could address these interests. Given the likely amount of time until MRO data requests could be fulfilled, those proposing EZs generally thought that another full-scale workshop focused on EZ proposals should not be attempted for approximately two years. However, there was broad interest in a series of workshops occurring on a more frequent basis. Perhaps the most frequently mentioned topic for one of these workshops was a more detailed discussion of ISRU-related site criteria as well as descriptions of candidate processing technologies.

\section{Building the community and maintaining momentum.}

There was general consensus that this Workshop was an excellent start to identifying a place where future human missions to Mars can productively explore this planet and learn to live and work there for the long term. The participants expressed a strong desire to maintain the momentum started by this Workshop, which was understood to include more extensive analyses of the EZs presented and building the community of science and resources/engineering interests that came together to carry out these EZ analyses. A series of workshops along the lines described above was viewed as one means to maintain momentum by setting tangible deadlines with specific objectives. Other mechanisms, such as a web portal supporting a repository of analysis results and other relevant materials as well as allowing contact among interested individuals or groups, were proposed as a positive means to build a sense of community.

The breadth of the interested community itself was also recognized as an aspect of community building that will require additional effort. Other components of the aerospace community, such as those more directly involved with human spaceflight operations (e.g., the astronaut corps as well as the planners and controllers of human space missions) plus a broader sweep of the mining and materials processing industry, were recognized as possessing important experience and insight that should be incorporated into the EZ assessment process as early as possible. Mechanisms such as those discussed above represent a portion of the means to engage these prospective stakeholders but additional mechanisms are likely to be required to raise awareness that this EZ analysis effort is underway and would benefit from an expanded participation. The enthusiasm exhibited at this first Workshop indicates that this is a topic of great interest and should be easily expanded to incorporate the broad spectrum of specialized groups needed to select the first Mars Exploration Zone.

\section{Conclusion}

This paper summarizes the current state of NASA's effort to identify viable locations for future human missions to Mars and the activities that contributed to this current state. At present NASA is assessing different options for conducting future human missions to Mars by means of coordinated studies, the results of which are assembled into an end-to-end description known as the Evolvable Mars Campaign (EMC). NASA's Human Exploration and Operations Mission Directorate (HEOMD) and the Science Mission Directorate (SMD) are cooperating in this process as these candidate locations will be used by NASA as part of a multi-year effort to determine where and how humans could explore Mars. In the near term this process includes: (a) identifying locations that would maximize the potential science return from future human exploration missions, (b) identifying locations with the potential for resources required to support humans, (c) developing concepts and engineering systems needed by future human crews to conduct operations within a candidate location, and (d) identifying key characteristics of the proposed candidate locations that cannot be evaluated using existing data sets, thus helping to define precursor measurements needed in advance of human missions.

An initial step in this process was recently completed at a workshop cosponsored by HEOMD and SMD to identify viable EZs using criteria based on results from recent EMC studies of human Mars mission options along with current scientific objectives for Mars exploration maintained by MEPAG. Several important findings resulted from this Workshop:

1. There was strong consensus that, at a scale of 100 $\mathrm{km}$ (radius), multiple places on Mars exist that have both sufficient scientific interest to sustain multiple crews of exploring astronauts, AND potential resource deposits for ISRU. There is no rationale (at least at this point in the EZ selection process) to change the scale of the EZ (e.g. to something larger such as $150 \mathrm{~km}$ radius or something smaller such as a $20 \mathrm{~km}$ radius). 
2. There was agreement that new data types (needed for more definitive analysis of EZs) argued strongly for a new orbiter mission, and possibly one or more surface missions, to obtain these data.

3. Workshop participants strongly endorsed the concept of an Announcement of Opportunity to support more detailed analyses of EZs as described by the Workshop organizers.

4. There was general consensus that this Workshop was an excellent start to identifying a place where future human missions to Mars can productively explore this planet and learn to live and work there for the long term. The participants expressed a strong desire to maintain the momentum started by this Workshop, which was understood to include more extensive analyses of the EZs presented and building the community of science and resources/engineering interests that came together to carry out these EZ analyses.

5. Very few sites were proposed poleward of 45 degrees, even though by the guidelines set for this Workshop sites up to 50 degrees both north and south were allowed. This is significant primarily because higher latitudes put additional propulsive requirements on the ascent vehicle used by each crew; lower latitude sites translate into smaller propellant required to reach orbit.

Both HEOMD and SMD are now using these results to refine several aspects of this process including:
- Changes that should be made to the EZ criteria distributed prior to the workshop;

- Recommendations for improving the EZ selection process (compared to what was just completed for the first Workshop);

- Trends in additional data that are needed to better characterize EZs proposed at the workshop and how these data needs impact the design and operation of future robotic Mars missions;

- Better understanding of the different potential sources for water, including the ease of extraction and purification; and

- Using these proposed locations to develop "Reference EZs" for assessment purposes (primarily engineering assessments).

All of the steps, both recent and planned, are making important advances in preparing for a campaign of highly productive human missions on the surface of Mars. As noted during Workshop discussions Dr. James Green, director of the Planetary Science Division in NASA Headquarters' Science Mission Directorate, called the first human landing site workshop "historic." Dr. Green added that the results of this Workshop are "... really the start of making Mars real ... identifying the real locations for us to be able to land, work and do our science." 


\section{APPENDICES \\ APPENDIX A \\ Science Criteria for EZ Selection}

\section{INTRODUCTION}

The Human Science Objectives Science Analysis Group (HSO-SAG 2015) was tasked with outlining the set of science objectives that might be considered for a human mission to Mars in 2035. The team was also tasked with developing a set of ROI criteria from these scientific objectives that could be used to support ongoing human Landing Site (LS)/EZ selection work.

The team considered a forecast of the state of knowledge for the 2030's and concluded that although the coming Mars exploration missions and scientific research of the late 2010s and 2020s will make eagerly anticipated discoveries, it is unlikely that the high level science objectives and priorities for Mars will change significantly prior to 2030.

\section{SCIENTIFIC OBJECTIVES}

The scientific objectives listed below were identified considering intrinsic scientific merit, magnitude of the benefit of a proximal human, opportunity to make simultaneous observations from different vantage points, and opportunity to deliver scientific payloads of higher mass/complexity. The objectives are not prioritized across the different groups: Astrobiology (A), Atmospheres (B), Geology (C), and Cross Cutting (D). The Geology objectives (C1 and C3) are further informed by a set of questions identified below.

\section{Astrobiology}

A1. Past Life: search for and characterize past habitability potential in environments with highest preservation potential for ancient biosignatures.

A2. Determine if evidence of past life is present in such environments.

A3. Present Life: search for and characterize modern environments with high habitability potential for extant life.

A4. Determine if evidence of extant life is present in such environments.

A5. Investigate the exchange and cycling of material between the subsurface, surface and atmosphere.

A6. Investigate the complex chemistry (e.g., degree of covalency, organic chemistry and redox gradients) in the near surface, understand the mechanisms for organosynthesis, alteration and destruction.

\section{AtMospheric Science}

B1. Simultaneously quantify the atmospheric state and forcings near the surface at four or more locations supplemented by regular vertical atmospheric structure information.

B2. Constrain past climate states and atmospheric composition through analysis of samples from the Noachian and Hesperian, including trapped gases and inclusions.

B3. Characterize the local source and sinks in the dust, water and $\mathrm{CO}_{2}$ cycles, and the key parameters that determine these sources and sinks across a diversity of surfaces.

B4. Quantify photochemical and electrochemical cycles and potential subsurface trace gas sources through the measurement of trace gases, heterogeneous reactions and the electrical environment.

B5. Infer previous climate states and atmospheric composition under different orbital configurations through chemical and isotopic analysis of sediments and water ice emplaced during the Amazonian.

B6. Provide simultaneous context for near-surface atmospheric characterization through the global monitoring and quantification of the atmospheric state, forcings, and the distribution of airborne aerosols and trace gases.

\section{GEOSCIENCES}

C1. Characterize the composition of surface units and evaluate the diverse geologic processes and paleoenvironments that have affected the martian crust; determine the sequence and duration of geological events, and establish their context within the geologic history of Mars to answer larger questions about planetary evolution (to be refined based on discoveries during the next decade).

C2. Determine relative and absolute ages of geologic events and units, determine their history of burial, exhumation, and exposure, and relate their ages to major events through martian history.

C3. Constrain the dynamics, structure, composition and evolution of the martian interior, to answer larger questions about planetary evolution (to be refined based on discoveries during the next decade).

\section{ADDitional QUESTIONS}

Q1. How have the mineralogical and geochemical properties of martian igneous rocks changed over geological time and across global length scales, and how do these changes reflect changing conditions in the martian interior?

Q2. In what ways are the oldest martian rocks similar or different in composition or formation mechanism to the oldest terrestrial and/or lunar rocks? 
Q3. How has the mineralogy and geochemistry of alteration products changed over geological time (epochs and obliquity cycles), and what does that indicate about changing climate or subsurface environmental properties?

Q4. How do impacts disrupt and redistribute crust and mantle material?

Q5. What were the processes of magmatic activity on Mars, how did they change with time, does volcanism persist to the present, and how does this contribute to crustal formation and resurfacing?

Q6. What is the nature and diversity of tectonism (faulting and flexure) over martian geological history?

Q7. What was the role of ice-related processes in modifying the martian surface?

Q8. What was the history and abundance of surface water and groundwater on Mars, and how is this reflected in the sedimentary and geochemical record?

Q9. How has the atmosphere of Mars changed over time and how has it affected sedimentary and erosional processes?

Q10. What was the history of the martian dynamo, and what was the cause and history of its cessation?

Q11. What was the compositional and dynamical evolution of Mars' mantle?

Q12. What is the structure of the martian interior?

Q13. What was the origin of Mars and its thermal evolution?

Q14. What are the modern sources of seismicity on Mars and how do they relate in magnitude or location to global tectonic or structural processes that have been active in the past?

\section{Cross-Cutting}

D1. Assuming the mission accesses at least one significant concentration of water as part of its ISRU operations, evaluate that deposit for its implications to astrobiology, atmospheric science, and geology.

D2. Characterize the impact of humans on the martian environment.

D3. Evaluate variability in the martian radiation environment.

\section{ROI Criteria}

These science objectives were then used to construct a set of ROI criteria, which can be used to identify potential human LS/EZs on Mars with high potential for substantial scientific discovery. Two types of criteria were identified in this study: Threshold and Qualifying. The threshold criteria listed below can be viewed as the highest priority and a "must have" for any potential ROI. Qualifying criteria are other high priority criteria that address important science questions and that add breadth to the scientific potential of an ROI.

\section{Threshold}

- Access to deposits with a high preservation potential for evidence of past habitability and fossil biosignatures AND/OR presence of sites that are promising for present habitability, e.g., as a refugium.
- Both of these criteria were viewed as highest priority but finding a place on Mars that accomplishes both may be difficult. Therefore, these should be considered as an "and/or" requirement for inclusion in an exploration zone. At least one of these should be present, and an exploration zone that meets both is not required but highly desirable.

- Noachian and/or Hesperian rocks in stratigraphic context that have high likelihood of containing trapped atmospheric gasses.

- Specifically rocks that might effectively inform objective B2 and Q9 from the science criteria. In this case trapped gases might also include rocks/minerals formed from atmospheric constituents that would also help inform the state of the atmosphere at a particular time.

- Exposures of at least two crustal units that have regional or global extents, that are suitable for radiometric dating, and that have relative ages that sample a significant range of martian geological time.

- Access to outcrops with morphological and/or geochemical signatures (with preference given to sites that link the two) indicative of aqueous processes or groundwater/mineral interactions.

- Identifiable stratigraphic contacts and cross-cutting relationships from which relative ages can be determined.

\section{QUALIFYING}

- Access to deposits with high potential for containing organic matter (indigenous or exogenous) with various lengths of surface exposure.

- Presence of meteorological diversity in space and time.

- High likelihood of surface-atmosphere exchange of dust (e.g., aeolian and dust devil activity) and water across a diverse range of surface types (e.g., dust cover, albedo, thermal inertia, surface roughness, and rock abundance).

- Access to Amazonian-aged subsurface ice, high latitude water ice (e.g., polar layer deposits), and Amazonianaged sedimentary deposits.

- Although Amazonian aged subsurface ice is typically located in the polar regions, this criteria is included with the hope that future work may identify near-surface Amazonian ice nearer the equator.

- High likelihood of active surface trace gas sources.

- Surface trace gas sources are included here in anticipation of further results from MSL and future results from the Mars Trace Gas Orbiter. A convincing case for localized trace gas emissions on Mars would be highly pertinent to ROI discussions.

- Access to igneous rocks that can be clearly tied to one or more distinct igneous provinces and/or from a range of different martian time periods.

- Access to near-surface ice and/or glacial or permafrostrelated sediments.

- Access to Noachian or pre-Noachian bedrock units.

- Access to outcrops with remnant magnetization. 
- Access to diverse deposits from primary, secondary, and basin-forming impacts.

- Access to structural features that have regional or global context.

- Access to a diversity of aeolian sediments and/or landforms.
Although the scientific interpretation of individual sites on Mars may change with time, the overall science objectives should not significantly change with time. In many cases the ROI criteria are subject to scientific interpretation, so proposers should make the case for how their identified ROIs meet the criteria, drawing on any data and analysis to support their claim. 


\section{APPENDIX B \\ ICE CRITERIA FOR EZ SELECTION}

\section{INTRODUCTION}

The ISRU and Civil Engineering Working Group (ICE WG) was tasked with developing a set of objectives that satisfy NASA's general goal of a permanent, sustainable human presence on Mars that is Earth independent. NASA continues to make progress on the Evolvable Mars Campaign (EMC), examining alternatives that address all aspects of this goal from Earth launch, to Mars surface operations, to Earth return. The ICE WG focused on just those portions of the EMC dealing with achieving a permanent, sustainable presence on the surface of Mars that minimizes (ideally eliminates) reliance on Earth. This means developing a local capability to provide for basic human needs of air, water, food and shelter along with other critical operational needs such as power, fuel/propellants, and the ability to manufacture selected items.

For purposes of this Exploration Zone activity two broad categories - in situ resource utilization (ISRU) and civil engineering (CE) - were used to group these concepts. But there remains several concepts -food production, for example - that do not ideally fit into either of these categories, but nonetheless are important and are being considered. The remainder of this discussion is built primarily around the ISRU and CE groups but other concepts are included as appropriate.

\section{ISRU AND CE OBJECTIVES}

Three primary objectives have been identified for ISRU and $\mathrm{CE}$ at an EZ site on Mars. While other objectives may emerge, these three will be used as guidance for candidate EZ identification:

1. Demonstrate the ability to prospect for and extract useful commodities from local materials in a cost effective and sustainable fashion and begin using those commodities in nominal operations as soon as possible.

The highest priority commodity for this objective is water. Important but of a secondary priority are metals, silicon, and structural building materials. Water can be used for multiple purposes that are mission enabling or enhancing (e.g., propellant/fuel cell reactant production, life support, radiation shielding, plant growth, etc.). Metals will be important for in situ fabrication of spare parts and repairs.

2. Demonstrate the ability to manipulate the surface for infrastructure emplacement and protection of hardware.

The highest priority capability for this objective is foundation improvement and surface stabilization (including construction of landing pads, roads, berms, etc.). Of secondary priority are capabilities to build structures and enhance radiation shielding for the crew (and possibly plants, assuming food production is implemented). Each candidate site will exhibit strengths and weaknesses with respect to this objective. For example, berms and roads may be used to improve mobility around surface infrastructure elements and help to minimize vehicle maintenance. Selected areas may require manipulation of the surface to create a suitable foundation for surface infrastructure such as modular habitats or crop growth chambers. While very important, radiation shielding may be enhanced using water walls before surface material is required. But determining the potential value of using surface materials for radiation protection will be one of the unknowns that will be investigated. Thus each candidate site will be assessed for factors such as these and an overall site plan will be developed noting where improvements are required.

3. Demonstrate capabilities that reduce reliance on supplies from Earth using indigenous materials, resources, and the environment.

The highest priority capability for this objective is food production. Of secondary priority is in situ manufacturing and construction with locally derived feedstock. Food is one of the largest (perhaps the largest?) consumable items that must be imported from Earth in current mission scenarios, so the ability to produce food locally will help improve sustainability by reducing logistical mass requirements as well as improving crew health with the use of fresh food. An in situ capability to manufacture and construct items has a potentially broad range of options to consider, but collectively these will help to minimize long term costs, logistics, and crew risk.

\section{EZ/ROI SELECTION CRITERIA}

These objectives have been used to generate criteria to guide selection of candidate EZs for human crews. Every attempt was made to make these criteria as quantitative as possible to enhance their use in the candidate EZ identification process, but it was also recognized that data may not currently exist to definitively identify locations that meet these criteria. As a result, the term potential was introduced into some of these criteria to indicate indirect evidence that a candidate site meets one or more of these criteria. Sites that satisfy these "potential" criteria may become targets for gathering additional data using instruments on existing and future spacecraft, as well as the focus of specific analysis by qualified teams using existing and future data sets.

The following criteria are considered requirements:

1. The proposed EZ must have at least one location with access to raw material that exhibits the potential to (a) be used as feedstock for water-generating ISRU processes and (b) yield significant quantities (>100MT) of water. The raw material can be in the form of ice, ice/regolith 
mix, or hydrated minerals, and the top of the raw material deposit should be as close to the surface as possible.

The resource feedstock deposit must be of a size that is sufficient to support one or all of the following needs for several human missions: enhanced radiation shielding, life support, EVA, and propulsion. To meet all of these needs a quantity of water approaching $20,000 \mathrm{~kg}$ must be produced for each crew. If the raw material is in the form of hydrated minerals, then it must have a potential for a high concentration (greater that $5 \%$ by weight). The following figure is provided to illustrate the volume of material that must be acquired to realize a certain amount of water, based on the weight percentage of water contained in that raw material and using a U.S. football field as a representative surface area to be mined. For this particular example a quantity of approximately $14,000 \mathrm{~kg}$ was sought and the ISRU process was assumed to be able to extract up to $80 \%$ of the water at a production rate of $1.238 \mathrm{~kg} / \mathrm{hr}$ (thus requiring 480 days to produce all of the water). A similar analysis can be used to estimate the potential yield for candidate raw material sites of different areal extent and for different estimated water yield.

Mining this raw material is likely to occur when no crew are present at the site. Even if crew are present, little crew time is likely to be available to operate or supervise the mining operation. So the raw material should be in a form that can be easily mined by highly automated equipment. Due to this use of automated equipment, the location where the raw material is acquired must be sufficiently flat (TBD based on rover stability and loading design, but less than approximately $10^{\circ}$ ) to permit excavation and soil storage. Major natural obstacles along the most direct traverse between resource feedstock and usage area that exceed planned mining mobility platforms such as canyons, cliffs, vertical outcrops, and wide crevices must not be present. Rock size must be $<30 \mathrm{~cm}$ (TBD based on rover clearance) to prevent any impact to rover mobility. Rock distribution must not allow for impact to excavation operations.

The raw material must be located less than 3 kilometers from the ISRU processing plant and power infrastructure - the value of the raw material decreases with increased distance (i.e., increased transportation "costs") from processing point or utilization point. Terrain features must not prevent directline-of-site communications between the ISRU processing system and rover/excavators if possible (to avoid the need for communication repeaters). In addition, the raw material must be as close to the surface as possible; ideally no more than 1 meter beneath the surface. Buried raw material requires extensive removal of overburden and/or a multiple segment drill, decreasing the value of the raw material (i.e., added time and "cost" to remove the overburden).

The resolution for the data used to assess potential should be $<1000$ meters in scale, with a desired resolution $<100$ meters.

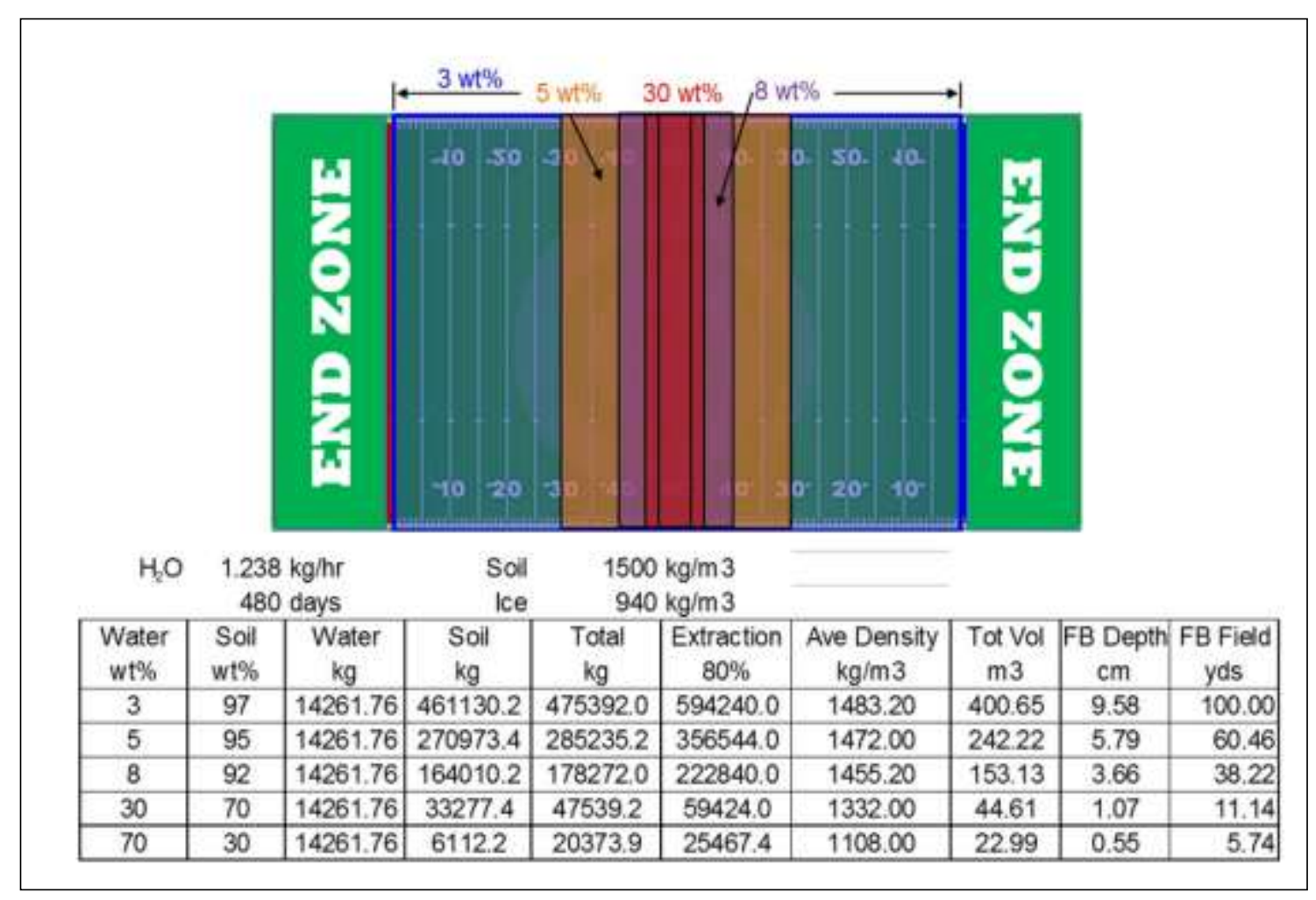

Figure 9 (Caption is TBD) 
2. Access to at least one region where infrastructure construction can be emplaced or constructed. This region must be less than 5 kilometers from a central landing site and contain flat, stable terrain. The region should exhibit evidence for an abundant source of cobble-sized or smaller rocks and bulk, loose regolith.

Within this construction region there should be no indication (or minimal indication?) of seasonal changes over the majority this area.

The identified raw materials (e.g., sand, cobbles, bulk regolith) are intended for use in a variety of construction techniques such as leveling roadways, enhancing roadway surfacing, constructing berms, burying habitats for radiation protection, etc. For reference, cobbles are defined as 64-256 $\mathrm{mm}(2.5-10 \mathrm{in})$ in size.

3. Access to raw material that exhibits the potential to be used as metal or silicon feedstock for ISRU and construction purposes. Of primary interest are iron, aluminum, and silicon; titanium and magnesium are of secondary interest. Raw material should be as near to the surface as possible and be in a form that is minable by highly automated systems.

The systems used to acquire the raw materials for use in these processes are likely to be similar to those used for acquiring raw material for processing into water. Thus the distance, depth, and features favorable to automated systems described previously for water ISRU also apply here.

The following criteria are considered enhancements. What this means is, for example, food production is very likely to be part of the activities taking place in the EZ, but there are options for implementing this capability that are site independent (e.g., hydroponically grown plants using artificial lighting). EZs satisfying these criteria could enhance the efficiency or reduce the Earth-supplied materials needed for the activity.

1. The proposed EZ may have additional locations with access to raw materials that exhibit the potential to be used as feedstock for water-generating ISRU processes. The raw material can be in the form of ice, ice/regolith mix, or hydrated minerals, and the top of the raw material deposit should be as close to the surface as possible.
The location of these additional raw material sites can be greater than 5 kilometers from the processing location or from point of use. Concentrations should be greater than $5 \%$ by weight to justify extended range operations from processing location or from point of use. A plausible traverse route must be evident for these additional sites (detailed assessments of traversability will be conducted separately). Terrain features must not prevent direct line-of-site communications between the ISRU processing system and rover/excavators if possible (to avoid the need for communication repeaters). Finally, slopes, rock size/distribution, and soil properties should allow for $\mathrm{road} / \mathrm{path}$ construction between the resource excavation location and centralized ISRU processing systems if these additional locations are required for sustained use.

2. Natural terrain features that can be adapted for construction purposes (e.g., to enhance habitat radiation protection) are considered an enhancement of the EZ. Examples include shallow depressions, narrow (but accessible) valleys, and lava tubes. Many of these terrain features are likely to be found within any EZ, but their value to the EZ will depend on their proximity to the centrally located infrastructure and the ease with which they can be adapted to these civil engineering purposes. Northern latitude sites below 40 degrees latitude are somewhat preferential due to less extreme climate variations and higher solar flux.

Food production is considered highly likely, but successful operations are not as dependent on the EZ location as other criteria described. Food production could be accomplished using hydroponically grown plants and artificial lighting. But food production could be implemented more efficiently (in terms of infrastructure required) if local regolith and natural lighting is used. With this in mind, an EZ with the following characteristics would be better suited to support food production: (a) a low latitude for more consistent lighting throughout the year, (b) no local terrain feature(s) that could shadow light collection facilities, (c) access to locally produced water, and (d) access to dark, minimally altered basaltic sands for use as soil base for crop growth; augmented with other material to improve crop growing potential. The locally acquired soils should avoid heavily weathered and/or altered soils (e.g., hydrothermal or fumarolic vent/systems) because they are likely to be more deficient in plant essential nutrients and thus require augmentation before they can be used. 


\section{APPENDIX C}

SteERING COMMITTEE MEMBERSHIP FOR THE FirST LANDING Site/EXPLORATION ZONE WORKSHOP FOR HUMAN MISSIONS TO THE SURFACE OF MARS

\begin{tabular}{|l|}
\hline Ben Bussey, Ph.D (NASA HQ/HEOMD) co-chair \\
\hline Richard Davis (NASA HQ/SMD) co-chair \\
\hline \\
\hline Anders Almeida (NASA HQ) \\
\hline David Beaty, Ph.D. (JPL) \\
\hline Marianne Bobskill, Ph.D. (NASA LaRC) \\
\hline Joshua Dunbar (NASA HQ) \\
\hline Matthew Golombek, Ph.D. (JPL) \\
\hline John Grant, Ph.D. (Smithsonian Institution) \\
\hline Lindsay Hays, Ph.D. (JPL) \\
\hline Stephen Hoffman, Ph.D. (SAIC) \\
\hline Robert Mueller (NASA KSC) \\
\hline Paul Niles, Ph.D. (NASA JSC) \\
\hline Larry Toups (NASA JSC) \\
\hline Richard Zurek, Ph.D. (JPL) \\
\hline
\end{tabular}




\section{APPENDix D}

\section{Summary of Proposed EZ and ROI Locations ANd Key Characteristics}

\begin{tabular}{|c|c|c|c|c|c|c|}
\hline \multicolumn{2}{|c|}{ Author } & Add'l Author(s) & Landing Site & Abstract No. & Longitude & Latitude \\
\hline Ackiss & Sheridan & Niles, P.B. & Huygens Crater & 1032 & 27 & $13.5 \mathrm{~S}$ \\
\hline Barker & Don & & Phlegra Dorsa & 1002 & 1 & $39 \mathrm{~N}$ \\
\hline Boatwright & Ben & & Southern Nectaris Fossae & 1005 & 2 & $29 \mathrm{~S}$ \\
\hline Calef & Fred & & Gale Crater & 1020 & 3 & $4.5 \mathrm{~S}$ \\
\hline Clarke & $\mathrm{J}$ & & Endeavour Crater & 1057 & 43 & $3 \mathrm{~S}$ \\
\hline Clifford & Stephen & & Eastern Valles Marineris & 1054 & 41 & $4 \mathrm{~S}$ \\
\hline Cohen & Barb & & Meridiani Planum & 1030 & 4 & $0.5 \mathrm{~N}$ \\
\hline Davila & Alfonso & Schulze-Makuch, D. & Hebrus Valles & 1012 & 5 & $20 \mathrm{~N}$ \\
\hline Farrell & Winslow & & Chryse - Viking & 1019 & 22 & $22.5 \mathrm{~N}$ \\
\hline Gallegos & Zachary & & Mesopotamia & 1035 & 28 & $35.5 \mathrm{~S}$ \\
\hline Gallegos & Zachary & & Protonilus Mensae & 1053 & 40 & $42 \mathrm{~N}$ \\
\hline Gallegos & Zachary & & Tempe Terra & 1056 & 42 & $42 \mathrm{~N}$ \\
\hline Gupta & Sanjeev & Sefton-Nash, E. & Hypanis & 1051 & 15 & $12 \mathrm{~N}$ \\
\hline Hamilton & John & & Ausonia Cavus & 1045 & 35 & $32 \mathrm{~S}$ \\
\hline Hamilton & John & & Kasei Valles & 1045 & 36 & $25 \mathrm{~N}$ \\
\hline Hamilton & John & & Ausonia Cavus & 1045 & 35 & $32 \mathrm{~S}$ \\
\hline Head & Jim & & Deuteronilus Mensae & 1033 & 9 & $39 \mathrm{~N}$ \\
\hline Hill & Jonathan & & Noachis Terra & 1021 & 23 & $37 \mathrm{~S}$ \\
\hline Horgan & Briony & & Mawrth Vallis & 1009 & 7 & $24.5 \mathrm{~N}$ \\
\hline Kerber & Laura & & Apollinaris Sulci & 1043 & 8 & $12.5 \mathrm{~S}$ \\
\hline Kochemasov & Gennady & & Vallis Marineris Mouth & 1006 & 10 & $20 \mathrm{~N}$ \\
\hline Laine & Pauli & & Newton Crater & 1015 & 20 & $40.5 \mathrm{~S}$ \\
\hline Lee & Pascal & & Noctis Landing & 1050 & 39 & $6.5 \mathrm{~S}$ \\
\hline Levy & Joe & & Hellas Rim & 1037 & 30 & $39 \mathrm{~S}$ \\
\hline Longo & Alex & & Gusev Crater & 1008 & 11 & $14.5 \mathrm{~S}$ \\
\hline Lynch & Kennda & & Columbus Crater & 1041 & 32 & $29 \mathrm{~S}$ \\
\hline Mangold & Nicolas & & Ismenius Cavus & 1027 & 19 & $33.5 \mathrm{~N}$ \\
\hline Markle & Loren & & Nili Fossae & 1010 & 12 & $22 \mathrm{~N}$ \\
\hline McEwen & Alfred & & Melas Chasma & 1007 & 13 & $12 \mathrm{~S}$ \\
\hline Michalski & Joe & & McLaughlin Crater & 1025 & 25 & $22 \mathrm{~N}$ \\
\hline Mitchell & Julie & & Equatorial Vallis Marineris & 1023 & 24 & $19 \mathrm{~S}$ \\
\hline Mojarro & $\mathrm{A}$, & Carr, C. & Coprates Chasma & 1036 & 29 & $11.5 \mathrm{~S}$ \\
\hline Montaño & Sui & & Gale Crater & 1040 & 3 & $4.5 \mathrm{~S}$ \\
\hline Mustard & Jack & & Jezero Crater & 1034 & 6 & $17.5 \mathrm{~N}$ \\
\hline Ori & Gian & & Firsoff Crater & 1026 & 14 & $0 \mathrm{~N}$ \\
\hline Plaut & Jeff & & Deuteronilus Mensae & 1044 & 34 & $41 \mathrm{~N}$ \\
\hline Rice & $\mathrm{Jim}$ & & Eastern Hellas & 1038 & 31 & $40 \mathrm{~S}$ \\
\hline Rice & Jim & & Apollinaris Sulci & 1046 & 37 & $13 \mathrm{~S}$ \\
\hline Sibille & Laurent & & Aram Chaos & 1048 & 38 & $2.5 \mathrm{~N}$ \\
\hline Skinner & Jim & & Hadriacus Palus & 1052 & 16 & $27 \mathrm{~S}$ \\
\hline Stillman & David & & Hale Crater & 1028 & 26 & $36 \mathrm{~S}$ \\
\hline
\end{tabular}




\begin{tabular}{|l|l|c|c|c|c|c|}
\hline \multicolumn{2}{|c|}{ Author } & Add'l Author(s) & Landing Site & Abstract No. & Longitude & Latitude \\
\hline Viola & Donna & & Erberus Montes & 1011 & 17 & $39 \mathrm{~N}$ \\
\hline Viola & Donna & & Acheron Fossae & 1011 & 18 & $40 \mathrm{~N}$ \\
\hline Westenberg & A & & Copericus Crater & 1029 & 44 & $49 \mathrm{~S}$ \\
\hline Wilkinson & Murray & McGovern, P.J. & Sinus Meridiani & 1042 & 33 & $2 \mathrm{~S}$ \\
\hline Wright & Shawn & & Cerberus & 1017 & 21 & $10 \mathrm{~N}$ \\
\hline Yun & Paul & & Gale Crater & 1022 & 3 & $4.5 \mathrm{~S}$ \\
\hline
\end{tabular}




\section{REFERENCES}

[1] S.3729 - National Aeronautics and Space Administration Authorization Act of 2010. Copied from https://www.congress.gov/bill/111th-congress/senatebill/3729. Copied on 19 October 2015.

[2] D. Craig; P. Troutman, and N. Herrmann (August 2015). Pioneering Space Through the Evolvable Mars Campaign. AIAA-2015-4409. AIAA Space 2015 Conference. Pasadena, CA

[3] Anon. (May 29, 2014). Pioneering Space: NASA's Next Steps on the Path to Mars. Copied from http://www.nasa.gov/sites/default/files/files/Pioneeringspace-final-052914b.pdf.

[4] Anon. (June 28, 2010). National Space Policy of the United States of America. Copied from: http://www.whitehouse.gov/sites/default/files/national_sp ace_policy_6-28-10.pdf

[5] B Drake (2009). Human Exploration of Mars: Design Reference Architecture 5.0. NASA/SP-2009-566A

[6] L. Toups and S. Hoffman (August 2015). Pioneering Objectives and Activities on the Surface of Mars. AIAA2015-4410. AIAA Space 2015 Conference. Pasadena, CA.

[7] Billick, I., Babb, I., Kloeppel, B., Leong, J.C., J. Hodder, J. Sanders, and H. Swain (2013). "Field Stations and Marine Laboratories of the Future: A Strategic Vision," National Association of Marine Laboratories and Organization of Biological Field Stations [http://www.obfs.org/fsmlfuture].

[8] MEPAG HEM-SAG (2008). Planning for the Scientific Exploration of Mars by Humans, Unpublished white paper, TBD p, posted March 2008 by the Mars Exploration Program Analysis Group (MEPAG) at http://mepag.jpl.nasa.gov/reports/index.html

[7] MEPAG (2015), Mars Scientific Goals, Objectives, Investigations, and Priorities: 2015. V. Hamilton, ed., 74 p. white paper posted June, 2015 by the Mars Exploration Program Analysis Group (MEPAG) at http://mepag.nasa.gov/reports.cfm.

\section{BIOGRAPHY}

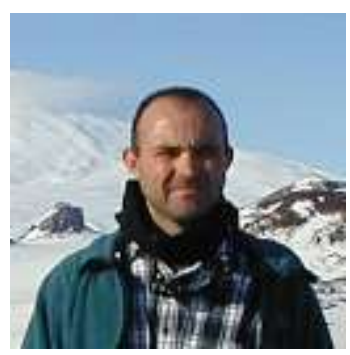

D. Ben J. Bussey is a planetary scientist who received a Ph.D. in planetary geology at University College, London, England. He specializes in the remote sensing of planetary surfaces. He coauthored an atlas of the Moon based on data and images from the Clementine mission. He has a particular interest in the lunar poles, using the Clementine images to locate crater cold traps for water deposits and mapping the so-called peaks of eternal light.

He worked at the Lunar and Planetary Institute in Houston and the European Space Agency before joining the Johns Hopkins University Applied Physics Laboratory (JHU/APL) and becoming a senior staff scientist at that facility. While there, Bussey served NASA as the principal investigator for the Mini-RF instrument onboard NASA's Lunar Reconnaissance Orbiter (LRO).

Additionally, Bussey served as a Principal Investigator (PI) for NASA SSERVI's “Volatiles, Regolith and Thermal Investigations Consortium for Exploration and Science (VORTICES)" team, and was also a PI for the NASA Lunar Science Institute, leading a team of researchers in the "Scientific and Exploration Potential of the Lunar Poles." His team furthered our understanding of the lunar polar regions, which were once regarded as "Luna incognita" (the unknown Moon)- now the lunar poles are as well known, and in some case better known, than the rest of the Moon. Thanks to the work of Bussey and his team, "luna incognita" became "luna cognita."

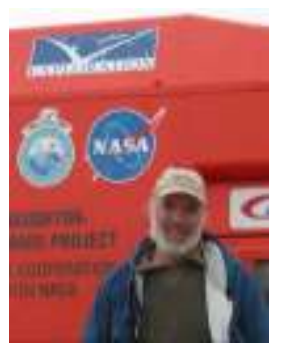

Stephen J. Hoffman received a B.S., M.S., and Ph.D. in Aeronautical and Astronautical Engineering from the University of Illinois in 1978, 1980, and 1984 respectively. Dr. Hoffman is a Senior Systems Engineer with 35 years of experience working in civilian space programs performing tasks involving program management, interplanetary mission planning, preliminary spacecraft design, orbit mechanics, and planetary analog missions. Dr. Hoffman is currently supporting the Exploration Mission Planning Office at the NASA Johnson Space Center. He supports a variety of mission studies and concept assessments associated with human exploration beyond low Earth orbit for this office. 